\title{
THE STABILITY PROBLEM OF THE HERMITE-HADAMARD INEQUALITY
}

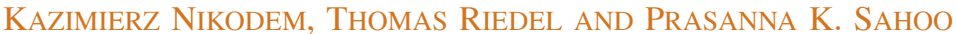

Abstract. The problem of the Hyers-Ulam stability of the Hermite-Hadamard inequality posed by Zs. Páles is solved. It is shown that for continuous functions $f: I \rightarrow \mathbb{R}$ neither the inequality $f\left(\frac{x+y}{2}\right) \leqslant \frac{1}{y-x} \int_{x}^{y} f(t) d t+\epsilon$ nor $\frac{1}{y-x} \int_{x}^{y} f(t) d t \leqslant \frac{f(x)+f(y)}{2}+\epsilon$ implies the $c \epsilon-$ convexity of $f$ (with any $c>0$ ). However, if $f$ is continuous and satisfies both of the above inequalities simultaneously, then it is $4 \epsilon$-convex.

Mathematics subject classification (2000): 39B82, 26 A51.

Ulam stability.

Key words and phrases: convex function, $\epsilon$-convex function, Hermite-Hadamard inequality, Hyers-

\section{REFERENCES}

[1] S. S. Dragomir, C. E. M. Pearce, Selected Topics on Hermite-Hadamard Inequalities and Applications, RGMIA Monographs, Victoria University, 2002. (ONLINE: http://rgmia.vu.edu.au/monographs/).

[2] D. H. Hyers, S. M. Ulam, Approximately convex functions, Proc. Amer. Math. Soc., 3, (1952), 821-828

[3] D. S. Mitrinović, L. B. LACKOvić, Hermite and convexity, Aequationes Math., 28, (1985), $229-232$.

[4] C. T. NG, K. Nikodem, On approximately convex functions, Proc. Amer. Math. Soc., 118, (1) (1993), 103-108.

[5] Zs. PÁLES, Problem 2. In: Report of the Fifth Katowice-Debrceen Winter Seminar on Functional Equations and Inequalities, February 2-5, 2005, Bedlewo, Poland. Ann. Math. Silesianae, 19, (2005), 76. 